\title{
Comparison between Freeters and Regular Employees: Moderating Effects of Skill Evaluation on the Age-Satisfaction Relationship
}

\author{
Yutaka Ueda $^{1} \&$ Yoko Ohzono ${ }^{2}$ \\ ${ }^{1}$ Faculty of Economics, Seikei University, Tokyo, Japan \\ ${ }^{2}$ Faculty of Contemporary Policy Studies, Josai University, Saitama, Japan \\ Correspondence: Yutaka Ueda, Faculty of Economics, Seikei University, 3-3-1, Kichijoji-kitamachi, \\ Musashino-shi, Tokyo 180-8633, Japan. Tel: 81-422-373-589. E-mail: ueda@econ.seikei.ac.jp
}

\author{
Received: February 22, 2013 \\ Accepted: April 2, 2013 \\ Online Published: April 17, 2013 \\ doi:10.5539/ibr.v6n5p100 \\ URL: http://dx.doi.org/10.5539/ibr.v6n5p100
}

\begin{abstract}
"Freeters" is a term used to describe workers who are employed in non-regular jobs. Freeters-unlike, for example, housewives or students - have no other primary roles in society. This article focuses on the effects of age on work satisfaction and compares the moderating effects of regular employees' and freeters' skill evaluation on age-satisfaction relationships. A hierarchical regression analysis based on data collected from 6,860 regular employees and 678 freeters demonstrated that age exerted a positive impact on regular employees' work satisfaction. However, age exerted a negative impact on freeters' work satisfaction. Further, the negative impacts of age were moderated by skill evaluation, such that the negative impact of age was much weaker when freeters highly evaluated their own skills.
\end{abstract}

Keywords: freeters, skill evaluation, work satisfaction

\section{Introduction}

This article focuses on differences in work satisfaction that occur between regular employees and "freeters." "Freeter" is a Japanese-English word used to refer to a certain type of non-regular employee. Freeters are generally recognized as working individuals between 15-34 years of age (female freeters are usually unmarried), who are not enrolled in school. Freeters are employed as "part-time" or "arbeit" workers (temporary workers). Individuals usually accept positions as regular employees following school graduation. Part-time positions are considered appropriate jobs for housewives or students who have other responsibilities in addition to employment. In contrast, one of the distinctive characteristics of freeters is that they choose not to be employed as regular employees, even though they have the ability or time to work full-time.

According to a survey conducted by the Ministry of Health, Labour and Welfare (MHLW) in Japan, the number of freeters peaked at 2.17 million in 2003. The total number of freeters decreased for five consecutive years. However, it increased again to 1.83 million in 2010 (White Paper on the Labour Economy, 2012). As revealed in the above-noted definition, freeters are a type of temporary workers. However, in a general Japanese sense, they appear to differ from typical part-time workers.

Freeters have attracted the attention of a number of Japanese researchers since the development of the bubble economy. Initially, many young Japanese people chose to become freeters during the bubble economy because they believed freeter positions would allow them to be independent workers who would be less dependent on organizations. In other words, freeters were favorably regarded as individuals who hoped to achieve their dreams while performing temporary work. However, as Japanese economic conditions deteriorated, many Japanese companies began to employ large numbers of young people as freeters to save on labor costs. Many young people had no other choice than to become freeters, even though they actually wanted to become regular employees. In fact, the average lifetime incomes for freeters equal only one-fourth the income of regular workers (see, http://social-success.info/entry56.html).

Further, freeters cannot avoid feeling anxious about their futures because they possess significantly lower job security than regular employees who remain secure because of the fixed terms of the employment system. As more people passively become freeters, in all likelihood, differences between freeters and regular employees will increase. Thus, more than ever before, it has become increasingly important to examine freeters' attitudes. 
However, although a number of studies have compared non-regular workers' situations to regular workers' situations, only a limited number of studies have focused on the development of freeters' attitudes and explored how freeters' attitudes may differ from regular employees' attitudes. In particular, this article aims to examine whether freeters' skill evaluation influence their work satisfaction and moderate the relationship that exists between age-satisfaction, using data collected from "Working Persons Data, 2010," a survey conducted by Recruit Works Inc. (RWI).

\section{Freeters' Motives to Become and Continue to Work as Freeters}

The Ministry of Health, Labour, and Welfare (MHLW) in Japan has defined "freeters" as individuals between the ages of 15 and 34 who have graduated from school (and, in the case of females, are unmarried), who are employed as the following types of workers: (1) Workers whose employment categories are determined by their employers as "part-time" or "arbeit" (temporary workers); (2) Unemployed individuals who are searching for part-time/arbeit jobs; and (3) Members of the non-labor force population who hope to find part-time/arbeit jobs, who are not otherwise engaged in household labor or education. Although the definition provided by MHLW appears most frequently in research literature, some other definitions of freeters have been proposed. For example, Abe (2005) argued that MHLW's definition does not necessarily reflect a general image of freeters. He proposed a new definition that describes freeters as individuals who have been employed as part-time or arbeit workers for less than five years. Further, Mori, Sakata, \& Yamada (2003) compared a variety of definitions provided for freeters. One of the main reasons why these definitions are not consistent is that young people often have different motives for becoming freeters.

Young people become freeters for a variety of reasons (Hoshi, 2005). Researchers have discovered three different types of freeters: moratorium types, dream-chaser types, and no-alternative types. Moratorium-type freeters consist of individuals who are willing to take positions as temporary workers for short periods because they do not yet want to enter the world of work. They realize the time will come when they will have to accept regular jobs. However, they hope the time has not yet arrived for them to move forward. Dream-chaser-type freeters dream of pursuing careers in the future. At times, their current temporary jobs may be related to their dream professions (e.g., a freeter who works at a law office who hopes to make his dream to be a lawyer a reality in the future). Yet, a woman who works at a restaurant who dreams of becoming a singer might maintain a current job that is irrelevant to her future dream career. Although these two types of freeter positions are positively chosen by individuals who hope to pursue other careers, at times, some individuals have no other choices except to become freeters, even though they initially wanted to become regular employees. This type of situation particularly affects no-alternative-type freeters.

Depending on the assumptions made about freeters' motives, images of freeters vary from positive (freedom, ease, or enjoyable) to negative (escape from future, low status, or dead-end) (Adachi, 2007; Ito, 2008; Katayama, 2008; Sugiyama \& Kanda, 2003). Although, in general, society has adopted negative views of freeters, some studies have shown that certain members of society will adopt positive views of freeters if they assume freeters have positive motives. For example, Tozuka (2008) discovered that students adopted different attitudes toward the above-mentioned three types of freeters. The students adopted the most favorable attitudes towards dream-chaser freeters.

Employees' work satisfaction is one of the most important topics in organizational behavior. Freeters' work satisfaction might differ depending on their aims or motives for accepting freeter employment. In particular, work satisfaction differs between individuals who positively chose freeter positions to fulfill their future goals, and individuals who are forced to become freeters because they have no other chances for employment as regular employees. Yet, individuals' initial motives to become freeters do not completely determine their work satisfaction. In fact, some individuals may become frustrated when they learn about the severity of actual vocational life, despite the fact that they positively chose to become freeters who maintain many dreams, and vice-versa.

One of the most important considerations is the effects of age and skill evaluation on individuals who choose to become freeters. First, in the case of regular employees, aging often results in higher status and higher salaries (particularly within the Japanese seniority system). Therefore, older regular employees are believed to be more satisfied with their work than their younger counterparts (Choi, 1997). However, with respect to freeters, aging signifies the shattering of dreams for dream-chaser-type freeters, and the development of progressively inextricable situations for no alternative-type freeters. Thus, with respect to freeters, it is possible that the effects of aging on work satisfaction will be negative, unlike the effects of aging on the regular employees' work satisfaction. 
Skill evaluation is a term used to describe how workers evaluate their own skills. Skill evaluation is believed to exert a positive effect on work satisfaction. If workers believe they have strong skills, they gain increased confidence when they perform challenging tasks and they gain enjoyment from completing these tasks (Houghton \& Jinkerson, 2007; Karatepe, Uludag, Menevis, Hadzimehmedagic, \& Baddar, 2007; Schyns, \& Sczesny, 2010). This concept holds true for both regular employees and freeters. However, with respect to freeters, if aged persons who continue to settle for positions as freeters strongly evaluate their skills, they will continue to maintain their dreams and ignore hardships inherent in freeter positions. In other words, skill evaluation exerts a moderating effect on the age-satisfaction relationship with respect to freeters. Although his research did not focus on elderly freeters, Yamamoto (2009) revealed that individuals who were more tolerant of freeters and who possessed stronger self-efficacy had more intense orientation toward self-growth and challenging career than those who were similarly tolerant of freeters but possessed weaker self-efficacy. These orientations helped them look away from disadvantages that resulted from aging within both their organizations and within society.

It might be argued that skill evaluation may consistently exert a moderating effect on the age-satisfaction relationship regardless of employment status. However, because most regular employees are believed to have acquired current employment statuses similar to statuses they had initially desired, regular employees will experience less frustration. They will not experience the type of frustration caused by feeling stuck in unstable situations experienced by freeters, even if regular employees believe they possess weak skills. Therefore, with respect to regular employees, the effects of aging and skill evaluation are believed to be independent of one another.

\section{Hypotheses}

Based on the discussion presented above, we propose the following hypotheses. First, regular employees are promoted and provided with important, satisfying jobs as they age. In particular, this occurs under the Japanese seniority system that still pervades most Japanese organizations. It is believed that regular employees' work satisfaction will increase as they get age. In contrast, freeters begin to realize how difficult it can be to make their dreams come true. They may relinquish their dreams as they age. In comparison with regular employees, freeters have limited opportunities to assume important responsibilities within their organizations. In contrast to regular employees, freeters will become increasingly dissatisfied with their work as they age. Therefore, we propose the following hypotheses:

H1: Age will exert a positive effect on work satisfaction with respect to regular employees.

H2: Age will exert a negative effect on work satisfaction with respect to freeters.

Each working individual occasionally wonders whether his/her skills contribute benefits to his/her organization. When working individuals highly evaluate their own skills, they can increase their self-confidence. In addition, they will feel reassured that they are considered worthwhile to their organizations. These factors will help them feel more satisfied with their work, regardless of their employment status. Therefore, we propose the following hypothesis:

H3: Skill evaluation will exert a positive effect on work satisfaction with respect to both regular employees and freeters.

Finally, as freeters age, they begin to realize that their dreams will no longer come true. If they believe they will be able to maintain skills strong enough to enable them to change their present work situations, the negative effects of aging on work satisfaction will be weakened. This means that the negative effects of aging on work satisfaction will differ based on freeters' evaluation of their own skills. In contrast, regular employees' skill evaluations fail to exert this type of moderating effect because regular employees do not experience feelings of disappointment as they age. Thus, we propose the following hypothesis that is solely related to the moderating effects of skill evaluation with respect to freeters.

H4: Skill evaluation will moderate the relationships between age and work satisfaction with respect to freeters because the negative effects of age on work satisfaction will be weaker when freeters possess strong skill evaluation than when freeters possess weak skill evaluation.

\section{Research Method}

\subsection{Sample}

Data collected from the "Working Persons Survey, 2010" were used in this study. The "Working Persons Survey" has been conducted every two years since 2000 by Recruit Works Inc. (RWI). The last survey was conducted in 
2010. RWI deposited this data in the Social Science Japan Data Archive (SSJDA), at the Center for Social Research and Data Archives, Institute of Social Science, The University of Tokyo, and SSJDA gave us permission to use this data. RWI surveyed more than 9,000 working individuals between the ages of 18 and 59 who lived in the Tokyo metropolitan area. These working individuals consisted of regular employees, contracted employees, freeters, part-timers, contingent employees, and others. However, this study used data solely from regular employees $(\mathrm{N}=6,860)$ and freeters $(\mathrm{N}=678)$.

\subsection{Measures}

We conducted a correlation analysis and a hierarchical regression analysis. We adopted the following measures as independent or dependent variables.

Age: Respondents' real ages were used as variables.

Skill evaluation: Skill evaluation was measured based on the average of responses to fifteen questions that ranged from [1] "I do not have (the following skill)" to [5] "I have sufficient skills in (the following skill)." Questions ranged between items related to analytical skills, items related to human relationship skills, and items related to current job-related skills. Sample items included, "Skills to build better human relationships," "Skills used to collect and analyze information to clarify problems," and "Skills and knowledge required to perform my current job." Cronbach's alphas equaled 0.908 for the regular employees' sample and 0.919 for the freeters' sample.

Work satisfaction. Employees derive work satisfaction from a variety of sources. An average of responses to three Likert-type questions queried the extent of respondents' satisfaction with their jobs, workplaces, and employment organizations was used. Cronbach's alphas equaled 0.891 for the regular employees' sample and 0.909 for the freeters' sample.

Gender: Genders ([1] male, [2] female) were used as control variables for the regression analysis.

\section{Results}

\subsection{Differences in Work Satisfaction Based on Employment Status and Gender}

Table 1 shows the differences in averages of work satisfaction based on employment status and gender. First, work satisfaction for male freeters $(\mathrm{mF})$ was significantly lower than work satisfaction for male regular employees (mR). In contrast, work satisfaction for female freeters (fF) failed to differ from work satisfaction for female regular employees (fR). Female freeters (fF) demonstrated significantly greater work satisfaction than male freeters $(\mathrm{mF})$. Further, gender appeared to exert consistent effects on work satisfaction. Regardless of employment status, female employees demonstrated greater work satisfaction than male employees.

This result might signify that freeters' positions differ between male and female employees. With respect to male employees, their first priority as adults is probably to gain employment as regular employees. Male freeters' lower satisfaction than male regular employees means their gaining employment as freeters is, in most cases, the result of passive choices. In contrast, female employees appear to face situations that differ from males' situations. Female freeters did not express weaker work satisfaction than female regular employees. Female freeters demonstrated greater work satisfaction than male freeters. This may signify that a considerable proportion of females positively chose to become freeters.

Table 1. Work satisfaction based on employment status and gender

\begin{tabular}{lll}
\hline Employment status & Male $(\mathrm{m})$ & Female (f) \\
\hline Regular Employees $(\mathrm{R})$ & 3.2974 & 3.3498 \\
$(\mathrm{~N}=6,860)$ & $(\mathrm{N}=4,913)$ & $(\mathrm{N}=1,947)$ \\
\hline Freeters $(\mathrm{F})$ & 3.1034 & 3.3505 \\
$(\mathrm{~N}=678)$ & $(\mathrm{N}=387)$ & $(\mathrm{N}=291)$ \\
\hline
\end{tabular}

Note: Significant differences $(\mathrm{p}<5 \%): \mathrm{mR}>\mathrm{mF}, \mathrm{mR}<\mathrm{fR}, \mathrm{mF}<\mathrm{fF}$.

\subsection{Basic Statistics and Inter-Correlations}

Table 2 displays basic statistics, reliabilities (Cronbach's alphas), and inter-correlations for variables related to regular employees and freeters. With respect to correlations, correlations related to regular employees are displayed on the lower left side of Table 2. Correlations related to freeters are displayed on the upper right side of Table 2. Reliabilities are depicted as a diagonal line (the left side depicts regular employees and the right side depicts freeters). 
When we compare the correlations, we discover several similarities or dissimilarities based on employment status. First, gender demonstrates a significant negative correlation with skill evaluation for the regular employees' sample $(\gamma=-.116, \mathrm{p}<.001)$, but does not demonstrate a significant negative correlation with skill evaluation for freeters $(\gamma=-.011$, n.s.). Two possible reasons may explain why male regular employees possess higher evaluation of their own skills than female regular employees. First, male regular employees are the sole employees provided with challenging tasks that enhance their skills. Second, employment as regular employees inspires male employees' confidence in their own skills because their specific culture encourages them to believe that only regular employees are highly skilled, whether or not this is true. Unfortunately, it is difficult to confirm which explanation is reflected in regular employees' actual situations based on this data.

The correlations between age and other variables were not similar based on employment status. In particular, the correlation between age and work satisfaction should be noted. With respect to regular employees, the correlation was significantly positive $(\gamma=.068, \mathrm{p}<.001)$. This means older employees demonstrated greater satisfaction with their work than their younger counterparts. However, a similar correlation did not appear in the freeters' sample $(\gamma=-.070$, n.s.). Based on this correlation analysis, freeters' ages apparently did not exert effects on their work satisfaction, although we assumed that older freeters were less satisfied with their work than younger freeters because the proportion of "no-alternative type" freeters was higher for old freeters than for young freeters. However, this simple correlation analysis ignores the effects of factors other than age. We expect that the regression analysis provided in the next section will reveal relationships that are more complicated.

Table 2. Basic statistics and inter-correlations related to variables

\begin{tabular}{|c|c|c|c|c|c|c|c|c|}
\hline \multirow{2}{*}{ Variables } & \multicolumn{2}{|c|}{ Regular Employees } & \multicolumn{4}{|c|}{ Correlations } & \multicolumn{2}{|c|}{ Freeters } \\
\hline & Means & Std Dev & Gender & Age & Skill Evaluation & Work Satisfaction & Means & Std Dev \\
\hline Gender & 1.284 & .451 & - & .011 & -.011 & $.136^{* *}$ & 1.429 & .495 \\
\hline Age & 39.380 & 10.247 & $-.147 * *$ & - & $.117 * *$ & -.070 & 28.090 & 9.138 \\
\hline Skill evaluation & 3.654 & .596 & $-.116^{* *}$ & $.263 * *$ & $.908 / .919$ & $.164 * *$ & 3.356 & .683 \\
\hline Work satisfaction & 3.312 & .877 & $.027 *$ & $.068 * *$ & $.159 * *$ & $.891 / .909$ & 3.209 & .899 \\
\hline
\end{tabular}

Notes: $\mathrm{N}=6,860$ (regular employees); $\mathrm{N}=678$ (freeters); ** : $\mathrm{p}<.01 ; *: \mathrm{p}<.05$.

\subsection{Results of Hierarchical Regression Analyses}

Tables 3 and 4 illustrate the results of the hierarchical regression analyses. Work satisfaction served as a dependent variable. In this analysis, demography variables, such as gender and age, were entered in the equation during the first step (Model 1). Then, skill evaluation was entered (Model 2). Finally, to discover the moderating effects of skill evaluation on age, the products of two variables were entered (Model 3).

First, with respect to Model 1, gender consistently exerted a significant positive impact on work satisfaction in both samples. This means that female employees tended to have greater work satisfaction than their male counterparts regardless of differences in employment status $(\beta=.137, \mathrm{p}<.001$ for regular employees; $\beta=.038$, $\mathrm{p}=.002$ for freeters). This result corresponds to the results of the correlation analysis described above. Second, the effects of age differed between regular employees and freeters. The results of the significant positive coefficient of age in the regular employees' sample signified that older regular employees tended to have greater work satisfaction than their younger counterparts $(\beta=.074, \mathrm{p}<.001)$. This result supports H1. However, although it was not as strong a relationship, age exerted a negative impact on work satisfaction in the freeters' samples $(\beta=-.071, \mathrm{p}=.061)$. This was also reflected in the results of the correlation analysis discussed in the previous section. This result supports $\mathrm{H} 2$.

Skill evaluation exerted a significant positive impact on work satisfaction in both samples $(\beta=.156, \mathrm{p}<.001$ for regular employees, $\beta=.176, \mathrm{p}<.001$ for freeters). This means, for both regular employees and freeters, employees who highly rated their own skills tended to have greater work satisfaction than employees who rated their own skills at lower levels. Thus, H3 was supported. Finally, the products of age and skill evaluation were significantly positive in the freeters' sample $(\beta=.093, \mathrm{p}=.017)$. However, the products were not significant in the regular employees' sample ( $\beta=-.013$, n.s.). This means that, in the freeters' sample, some moderating effects between age and skill evaluation were apparent. However, the effects of these two variables were independent in the regular employees' sample. 
Table 3. Results of the hierarchical regression analysis (regular employees)

\begin{tabular}{|c|c|c|c|c|c|c|c|c|}
\hline & & \multicolumn{2}{|c|}{ Unstandardized Coefficient } & \multirow{2}{*}{$\begin{array}{l}\text { Standardized Coefficients } \\
\text { (Beta) }\end{array}$} & \multirow{2}{*}{$\mathrm{t}$} & \multirow{2}{*}{ Sig. } & \multirow{2}{*}{$\begin{array}{c}\triangle R^{2} \\
\operatorname{adj} R^{2} \\
\end{array}$} & \multirow{2}{*}{$\begin{array}{l}\triangle F \\
F\end{array}$} \\
\hline \multicolumn{2}{|c|}{ models } & $\mathrm{B}$ & Std Error & & & & & \\
\hline \multirow[t]{3}{*}{1} & (Constant) & 2.969 & .056 & & 53.417 & $<.001$ & & \\
\hline & Gender & .074 & .024 & .038 & 3.104 & .002 & .006 & $20.930 * *$ \\
\hline & Age & .006 & .001 & .074 & 6.072 & $<.001$ & .006 & $20.930 * *$ \\
\hline \multirow[t]{4}{*}{2} & (Constant) & 3.070 & .056 & & 55.289 & $<.001$ & & \\
\hline & Gender & .098 & .023 & .050 & 4.153 & $<.001$ & & \\
\hline & Age & .003 & .001 & .035 & 2.785 & .005 & .023 & $159.251 * *$ \\
\hline & Skill Evaluation & .230 & .018 & .156 & 12.619 & $<.001$ & .028 & $67.359 * *$ \\
\hline \multirow[t]{5}{*}{3} & (Constant) & 3.072 & .056 & & 55.294 & $<.001$ & & \\
\hline & Gender & .098 & .023 & .050 & 4.170 & $<.001$ & & \\
\hline & Age & .003 & .001 & .035 & 2.795 & .005 & & \\
\hline & Skill Evaluation & .228 & .018 & .155 & 12.491 & $<.001$ & .000 & 1.113 \\
\hline & Age*Skill Evaluation & -.002 & .002 & -.013 & -1.055 & .291 & .028 & $50.798 * *$ \\
\hline
\end{tabular}

Table 4. Results of the hierarchical regression analysis (freeters)

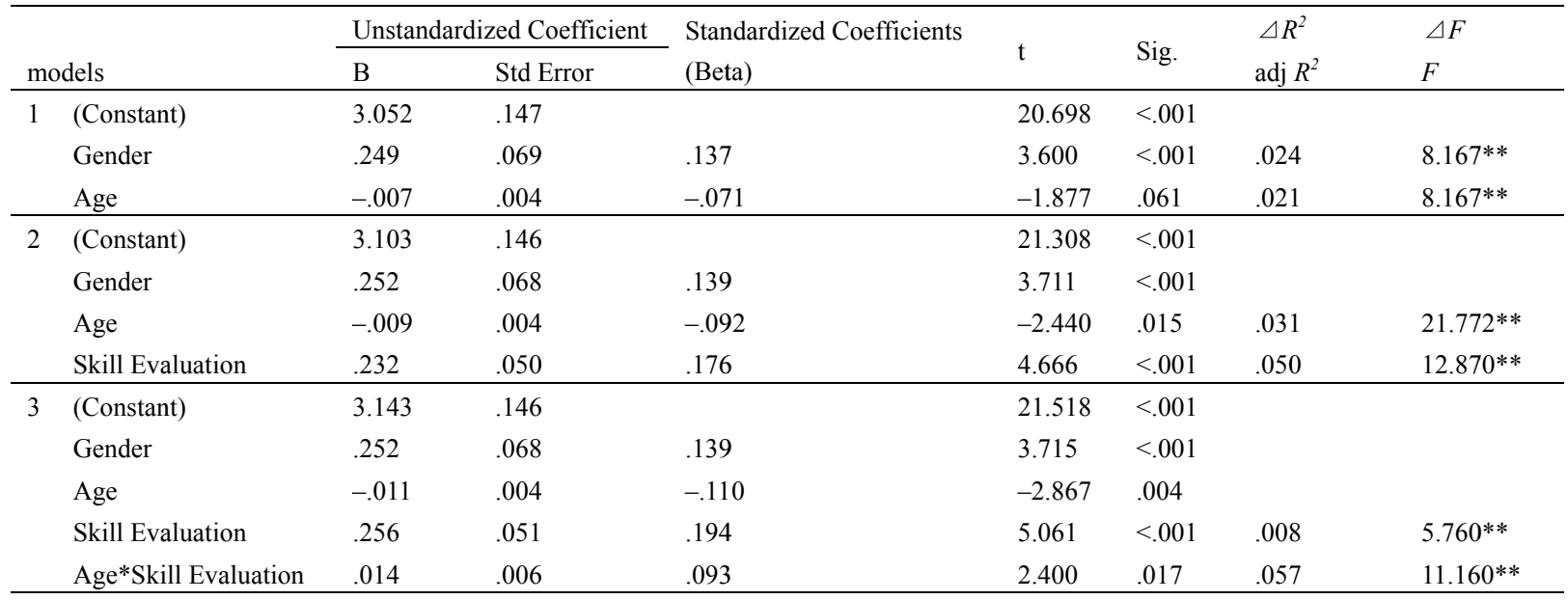

Figure 1 depicts the moderating effect of skill evaluation on the effects of age on work satisfaction with respect to freeters. Although age exerted a negative effect on work satisfaction, this effect was significantly weaker when freeters highly evaluated their skills, rather than when freeters evaluated their skills at lower levels. A good illustration of this effect is provided in Figure 1. This result supported H4.

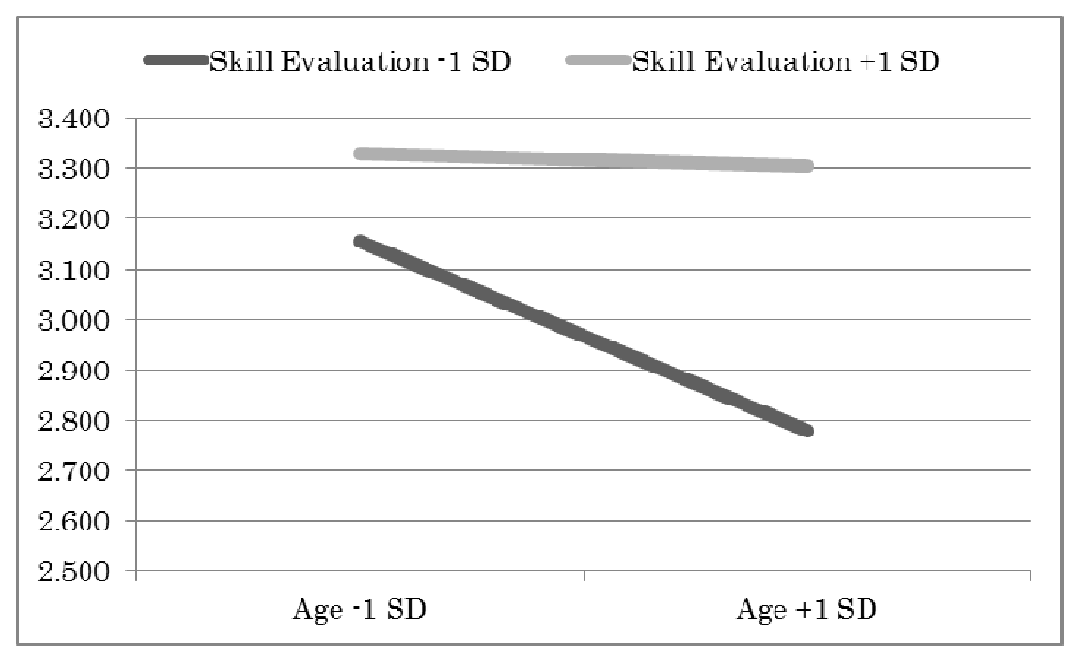

Figure 1. Moderating effects of skill evaluation on the effects of age on work satisfaction 


\section{Discussion and Conclusions}

This article aimed to discover differences in the effects of age on work satisfaction, as well as its moderating effects on the age-satisfaction relationship that exists between regular employees and freeters. Empirical result supported all four hypotheses we proposed. Because of the harsh economic situation in Japan, the increasing employment freeters continues to cause significant problems for Japanese society. Legal systems that hope to improve economic and social conditions of temporary workers, including freeters, have gradually been established in Japan. However, a challenge of equal importance as the establishment of legal systems is the discovery of effective ways to motivate temporary workers who are more likely to lose their motivation to work because they are employed in low positions in their organization. This article suggests the importance of considering the attitudes of temporary workers, such as freeters.

One of the most important goals of human resource management in organizations is to increase employees' work satisfaction. This article demonstrated the important role of freeters' enhanced skill evaluation on their work satisfaction. However, as discussed previously, different types of freeters work for different organizations. It might not always be possible to enhance the actual skills of some types of freeters. In particular, it might be more difficult to train elderly freeters because they frequently lack the flexibility to adapt to new technology and work environments. However, one of the more important and effective ways to assist freeters would be to change their perceptions of their usability in organizations. A variety of specific methods aimed at the improvement of self-discovery for elderly freeters should be adopted by organizations.

This research has several limitations. First, although this article compares freeters with regular employees, other types of employees also operate in the workplace, such as contingent employees, contracted employees, and part-timers. The distinction between freeters and part-timers is not based on employers' positioning. Rather, it is based on employees' conditions. In other words, the distinction is based on whether employees possess other social positions (e.g., housewives or students). Therefore, determination of the differences between freeters and part-time workers is an important topic for future research.

Second, in this study, a problem occurred related to the data collection method. RWI asked respondents to select appropriate categories from multiple employment statuses. However, because of the ambiguity inherent in the definition of freeters, or because of their complicated images, the ways that respondents interpreted and discerned these categories was unclear. In particular, the word, "freeters" has both positive and negative implications. It remains unclear whether respondents who maintained negative assumptions about freeters were willing to choose "freeters" as their employment status category, even though their work statuses met the definition for freeters. Therefore, if only those persons who positively evaluated freeters chose freeters, then the freeters' sample for this survey might have been biased to a certain degree.

Finally, although our study used an overall skill evaluation measure that was calculated by averaging responses to fifteen items, some distinctive skills may have been evaluated differently by working persons. Although skill evaluation was found to serve as a moderator on the age-satisfaction relationship, evaluation of different aspects of skills might have exerted a different moderating effect on that relationship depending on the deterioration of freeters' future expectations as they age.

Despite these limitations, to our knowledge, this is the first study to focus on the variety of moderating effects of skill evaluation that occur between regular employees and freeters. Future studies will improve our research framework and adopt more rigorous methods to determine factors that affect freeters' work situations and attitudes.

\section{References}

Abe, Y. (2005). A note on freeters [in Japanese]. Journal of Economics, Asia University, 29(3), 75-85.

Adachi, T. (2007). Structure and determinants of affirmative attitudes among Japanese youth regarding part time workers known as freeters [in Japanese]. The Japanese Journal of Experimental Social Psychology, 47(1), 39-50. http://dx.doi.org/10.2130/jjesp.47.39

Bandura, A. (1997). Self-efficacy: The exercise of control. New York: Freeman.

Bandura, A. (2001). Social cognitive theory: An agentic perspective. Annual Review of Psychology, 52(1), 1-26. http://dx.doi.org/10.1146/annurev.psych.52.1.1

Choi, E. S. (1997). Environmental changes and morale of working people: Focusing on the business cycle and job satisfaction [in Japanese]. Mita Business Review, 39(6), 59-67.

Hoshi, M. (2006). Freeter in Chiba: Questionnaire survey report (from May to August 2005) [in Japanese]. The 
annual bulletin of the Institute for Economic and Cultural Studies, 11, 89-117.

Houghton, J., \& Jinkerson, D. (2007). Constructive thought strategies and job satisfaction: A preliminary examination. Journal of Business and Psychology, 22(1), 45-53. http://dx.doi.org/10.1007/s10869-007-9046-9

Ito, K. (2008). A study on the images of freeters and "neet" [in Japanese]. The Journal of Kamakura Women's University, 15, 43-50.

Karatepe, O. M., Uludag, O., Menevis, I., Hadzimehmedagic, L., \& Baddar, L. (2006). The effects of selected individual characteristics on frontline employee performance and job satisfaction. Tourism Management, 27(4), 547-560. http://dx.doi.org/10.1016/j.tourman.2005.02.009

Katayama, Y. (2008). Dropouts and the labor market for high school graduates: From the viewpoint of the acceptance of becoming a freeter [in Japanese]. The Journal of Educational Sociology, 83, 23-43.

Mori, H., Sakata, Y., \& Yamada, S. (2003). Concept of the job-hopping part-time workers "the so-called freeter" and its statistical expansion [in Japanese]. Economic Review, 71(1), 1-23.

Schyns, B., \& Sczesny, S. (2010). Leadership attributes valence in self-concept and occupational self-efficacy. Career Development International, 15(1), 78-92. http://dx.doi.org/10.1108/13620431011020907

Sugiyama, S., \& Kanda, N. (2003). Freeter-related attitudes in university students [in Japanese]. Seikatsu Kagaku Kenkyu, Institute of Living Science Bunkyo University, 25, 29-39.

Tozuka, T. (2008). University students' attitudes toward chasing dream types, aimless types, and unwilling types of part-time workers [in Japanese]. The University Bulletin of Chiba Institute of Science, 1, 81-88.

Yamamoto, K. (2009). Japan's new innovators of the employment system? University students and their abilities to accept the world of the freeter [in Japanese]. Hyoronshakai kagaku, Social Science Review, 87, 95-116. 